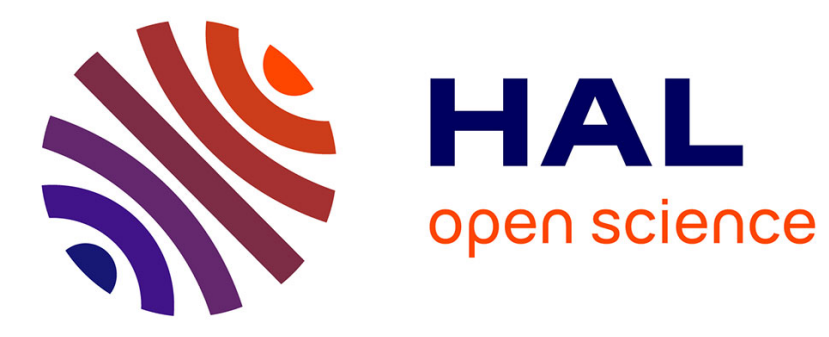

\title{
Human Resource Management in Japanese Firms Undergoing Transition: A Hierarchical Approach
}

\author{
Hiroatsu Nohara
}

\section{To cite this version:}

Hiroatsu Nohara. Human Resource Management in Japanese Firms Undergoing Transition: A Hierarchical Approach. Daniel Dirks; Jean-François Huchet; Thierry Ribault. Japanese Management in the Low Growth Era. Between External Shocks and Internal Evolution, Springer, pp.243-262, 1999, 978-3-642-63518-2. 10.1007/978-3-642-58257-8_16. halshs-02928906

\section{HAL Id: halshs-02928906 \\ https://shs.hal.science/halshs-02928906}

Submitted on 3 Sep 2020

HAL is a multi-disciplinary open access archive for the deposit and dissemination of scientific research documents, whether they are published or not. The documents may come from teaching and research institutions in France or abroad, or from public or private research centers.
L'archive ouverte pluridisciplinaire HAL, est destinée au dépôt et à la diffusion de documents scientifiques de niveau recherche, publiés ou non, émanant des établissements d'enseignement et de recherche français ou étrangers, des laboratoires publics ou privés. 


\title{
Human Resource Management in Japanese Firms Undergoing Transition; a Hierarchical Approach
}

\author{
Hiroatsu Nohara \\ Researcher at LEST-CNRS \\ Aix-Marseille University \\ LEST-CNRS \\ 35 Avenue Jules Ferry
}

13626 Aix-En-Provence Cedex, France

Email : hiroatsu.nohara@univ-amu.fr

This paper has been published in:

Nohara H. (1999) Human Resource Management in Japanese Firms

Undergoing Transition: A Hierarchical Approach. In: Dirks D., Huchet JF.,

Ribault T. (eds) Japanese Management in the Low Growth Era. Springer, Berlin,

Heidelberg.

https://doi.org/10.1007/978-3-642-58257-8_16 
The recession the Japanese economy is undergoing since the beginning of the 1990s has given rise to much questioning as to its nature. However, many analysts - irrespective of theoretical persuasion - seem to agree that it is structural rather than cyclical. In particular, they point to the increasingly glaring mismatch between the new conditions of competition in the international market and the institutional infrastructure which has grown up over the past fifty years, within the framework of the nation state, and provided the foundation for Japan's rapid economic growth. In other words, the various institutional mechanisms hitherto regarded as the keys to the country's economic success are falling into disuse and are even beginning to come into conflict with the current phase of economic globalisation. In short, the foundations of yesterday's success have become the source of today's impasse.

Such diagnoses cannot fail to call into question the Japanese model of the firm, a central plank of the institutional pacts that have constituted the engine of wealth production. The firm is indeed the site at which the various institutional forces converge in order to be transformed into productive capacity. It is obvious, even if the macro and micro levels tend to be confused in the various debates, that the fundamental issue for economists is to identify the limits of this model of the firm.

However, the main purpose of this paper is not to conduct an exhaustive analysis of the tensions that have become apparent in the Japanese model of the firm. Such a study is beyond the scope of this article. Rather, our objective is simply to investigate the nature of the changes that one of the elements of the model is undergoing, namely the management of human resources (HRM). However, anyone seeking to study the changes the model is undergoing will inevitably come up against two kinds of problem.

The first problem concerns the interpretation of the model. Although there is an extensive literature on human resource management in Japanese firms, there is still by no means any agreement on its general portrayal, or even on how the facts observed are to be interpreted (Ujihara 1958, Dore 1972, Koike 1976, Aoki 1988). The various interpretations that have arisen as a result have created a sense of confusion.

The second problem, more methodological in nature, concerns our ability to evaluate. It might legitimately be asked how change can be evaluated or measured when every subject of analysis, at least in the social sciences, is constantly on the move. Are we sufficiently well equipped with analytical tools to be able to capture the changes taking place in complex realities?

Without claiming to be able to resolve all these difficulties, we shall attempt in this paper to outline some possible responses to the problems raised. The starting point for this attempt will be the phenomenon of the hierarchy. 
In the neo-classical literature, no real reference is made either to organisations or to hierarchies; neo-institutionalist approaches, on the other hand, seek to develop economic tools that make it possible to analyse the "black box" that organisations constitute. Nevertheless, following Williamson (Williamson 1975), who introduces the opposition between market and hierarchy, the hierarchical organisation is regarded above all from the point of view of the allocation of informational resources, i.e. of the decision-making process; in contrast to the market, the hierarchy derives its efficiency from task specialisation and centralised decision-making. Such approaches tend, therefore, to play down the economic role of the hierarchy in the management of human resources. It is true that some studies (Akerlof and Yellen 1986) emphasise the economic rationalities of the "internal labour market" - another term for the hierarchy - in terms of "incentive theory", "moral hazard", "implicit contract", "risk aversion" on the part of workers, etc. However, most of these studies remain faithful to the principle of methodological individualism and adopt an analytical framework based on agency theory that reduces the employment contract to a simple bilateral relationship between principal and agent. From this perspective, the internal market is wholly devoid of any collective dimension and consists solely of innumerable individual contracts. Thus these neo-institutionalist approaches lead to a portrayal of the internal market that lacks the depth of the hierarchical organisation, takes no account of the interaction between the actors and appears to be without structure. In comparison with such a "dematerialised" internal labour market, the early works published by labour economists (Doeringer and Piore 1971) seem to offer a richer analytical framework. These authors focus their analysis on the internal management practices firms adopt in order to stabilise the workers they select and then train. Their model of the organisation usually includes a hierarchy of jobs, points of entry to that hierarchy and clearly marked routes along which employees move as they develop their skills. Structuring of this kind protects "insiders" from the competitive forces that weaken the position of "outsiders" in the external labour market. Thus they highlight the existence of an internal market that does not appear to operate in accordance with the principles of the walrasien market. On the contrary, labour allocation and pay determination in this internal market take place in accordance with rules specific to each firm. Thus it is the hierarchy that plays the central organisational role, thereby giving rise to the segmentation of spaces between the external and internal markets. Although they are not formalised to any great extent, these studies opened up an interesting new path that allows economic analysis to take account of the hierarchy. Apart from the few neo-institutionalist endeavours already alluded to above, it would appear to be Aoki (Aoki 1988) who managed to produce the most highly formalised account of the role of the hierarchy in HRM, while at the same time retaining the collective aspect of the production of skills. In particular, Aoki develops the notion of "rank hierarchy" (a set of incentives put in place within the internal market) by arguing that hierarchical principles can be used not only to resolve the problem of coordination (resource allocation, information flows) but also to address that of incentives (employee motivation). Without investigating the real core of his argument, we can follow Aoki to the 
extent of recognising that the hierarchical organisation - and the pay hierarchy that accompanies it - has three functions in the management of human resources.

1) It rationalises the learning process, since employees' progression from the simplest to increasingly complicated tasks can reduce training costs through the effects of "on-the-job training" and "learning by doing".

2) It encourages employees to maximise their efforts and to learn, not simply in the sense of resolving the "moral hazard problem", which is implied in the "shirking model", but also by making their progress up the hierarchy conditional upon their involvement in their work and the development of competencies over the long term.

3) It resolves the "adverse selection problem"; career paths based on progression up the hierarchy allow individual employees' abilities to be tested at each level of responsibility, thereby avoiding any mismatch between individuals and jobs.

These three economic functions fall into a universal category of rationality that can be applied to all forms of hierarchical organisation. We accept the validity of these statements and their general applicability, at least on a hypothetical level. However, our working hypothesis is that these functions, given material form in various management tools, are mobilised very differently from one country to another, depending on the way in which the firm is integrated into the wider society. It especially seems important to take into consideration the interdependency between educational system and work organisation in the firm. In this sense, what appears to be a universal rationality turns out be mediated to a considerable extent through a specific "societal rationality" (Maurice, Sellier, Silvestre 1986). This interpretative approach, which is close to the notion of "embeddedness between economic action and social structure" advanced by Granovetter (Granovetter 1985), will serve as a starting point for our investigations.

In the first part of this chapter, we will attempt to characterise the Japanese HRM model by conducting a comparison between France and Japan. The vast majority of comparative studies carried out in Japan take the Anglo-Saxon countries as their reference point, and a comparison with France might shed new light on the Japanese model. In the second part, we will examine the changes of direction brought about by the current recession.

\section{I - The construction of the hierarchy in Japan}

Our aim here is to synthesise, in the most stylised way possible, the various dimensions of the hierarchy in Japan, using the French hierarchy as a mirror in which to reflect and thereby form an image of its Japanese counterpart. We will begin by outlining the path taken by a few categories of employee along the pay hierarchy before turning our attention to some of the HRM principles that underpin the construction of the hierarchy. 


\section{I-1 Comparison of wage profiles}

Table 1 below shows the progression of several categories of employees along the pay scale in accordance with age. Although they are very crude, these wage curves provide some interesting information, not only on the structure of the hierarchy at any given time but also on career paths of dependent employees in the two countries.
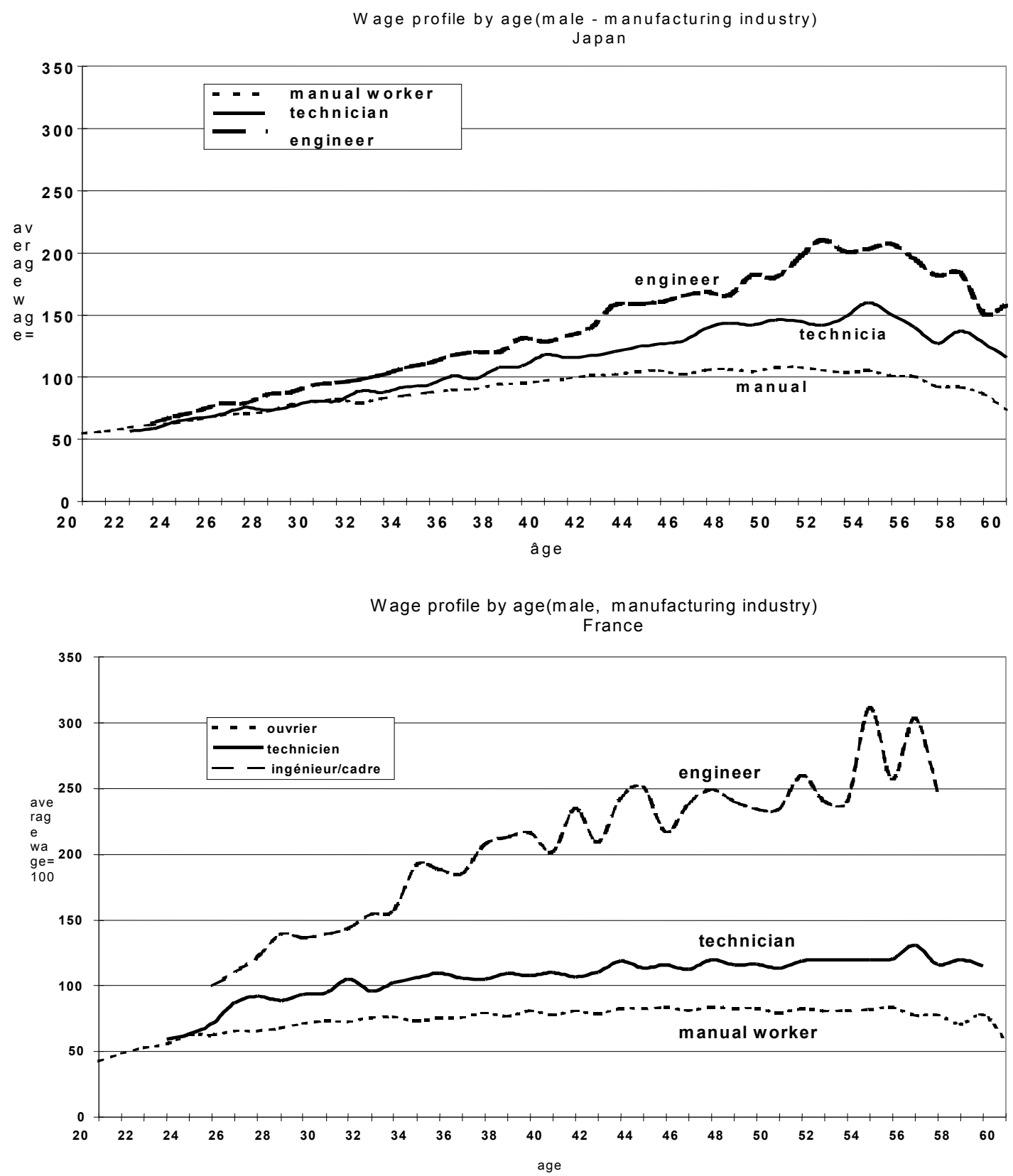
France is characterised by the coexistence of several forms of wage curves corresponding to various types of incentive, or to the absence of any incentive. In other words, the various categories of employee are treated in highly differentiated ways.

The wage curve of most manual workers in France reaches its peak very quickly. Whereas the pay of their Japanese counterparts continues to rise until the age of 45-49, that of French manual workers starts to stagnate after the age of 30 . Moreover, the earnings of French manual workers rise only modestly in the course of their working lives. At age 40-44, earnings are only $29 \%$ higher than at age 20-24, compared with an increase of $80 \%$ for engineers and managers (cadres). This absence of a career structure for manual workers seems to have several consequences. Firstly, pay does not seem to act as much of an incentive in the development of skills in this population. Secondly, promotion to a non-manual category, and particularly to the technician category, is a worthwhile prospect, but one that tends to diminish the status of the manual category, since many of the "better" workers are able to leave it. Thirdly, the absence of promotion prospects for most manual workers increases the distance between them and other categories, does not aid the establishment of trust and obstructs the development of cooperative working relationships within the firm. As far as technicians are concerned, they constitute an intermediate category with a weak professional identity. This category is in fact made up of two heterogeneous populations, one of which consists of promoted manual workers and the other of holders of a qualification requiring two years of post-baccalauréat study. In the case of the former, promotion to the technician category represents a worthwhile extension of their wage curves. In the case of the latter, who have the status of "senior technician", pay reaches a peak after only ten years in the labour market. For them, promotion to the engineer or cadre category is the only way of furthering their careers or increasing their pay. Cadres (managers) and engineers, in contrast, enjoy high status as soon as they graduate from the grandes écoles (the most elitist engineering schools) which gives them both a great deal of professional autonomy and a high salary. The pay of cadres (managers) aged 20-24 at the beginning of their careers is twice that of manual workers of the same age and equal to that of the highest paid technicians. Moreover, their wage curve does not reach its peak until they are aged between 50 and 54. A pay scale of this kind constitutes a real incentive mechanism.

Compared with the French situation, dependent employees in Japan are organised and mobilised in a very different way. Here, the wage curves for the various categories of employees are similarly shaped, rising rapidly to a peak and then falling away gradually. The only differences between the categories are the end points reached and the rate of progression. Manual workers, for example, reach their peak pay level at the age of $45-49$, when their pay is $78 \%$ higher than at age 20-24; managers and engineers, on the other hand, reach their peak pay level at age $50-54$, by which time their starting pay has almost tripled. These differences, essentially homothetic in nature, do not reveal any great split between the various categories of employee, unlike in France. In fact manual workers, technicians and engineers are all covered by a single status clause and, in many 
cases, by the same payment system. However, this overall homogeneity at the category level does not exclude pay individualisation based on the annual evaluation of each employee carried out by his superior. This individual evaluation of competencies applies to all categories, including manual workers, a practice that seems to set Japan apart from European countries (Koike 1981). In effect, therefore, firms are very subtly differentiating employees' pay within the limits of the career paths laid down ex ante for each category. In any event, pay tends to be a uniting factor for Japanese employees, at least at the beginning of their careers, unlike in France, where it has a divisive effect from the outset. It is only as they advance along their career paths that the narrow pay differentials began to widen gradually. Thus graduate engineers (with degrees requiring 4 or more years' higher education) and technicians with diplomas requiring 2 years' higher or further education begin their careers on salaries that differ little from those of manual workers of the same age (20-24). Their starting salaries constitute the minimum level of pay in the labour market. This dissociation between formal qualifications and pay, a phenomenon specific to Japan, runs counter to the teachings of the "signalling" and "adverse selection" theories. Furthermore, their pay levels remain lower than those of very experienced manual workers, at least until they are around 35 years of age. This slow rate of progress along the pay scale, which from a European point of view seems to offer little in the way of motivation, is accepted by young graduates, even though they are aware that it does not always encourage risk-taking or creativity. Nevertheless, the wage curve for non-manual workers does eventually diverge from that for manual workers. From the age of 35-40 onwards, it begins to accelerate, eventually reaching a peak that is more than double the pay of manual workers. As a result, managers and engineers at the end of their careers acquire professional recognition and legitimation through the hierarchy.

\section{I-2 Construction of occupational hierarchy}

After this analysis of pay, we shall turn our attention to the construction of the hierarchy. The diagrams reproduced below are intended to summarise some of the basic principles underlying the organisation of hierarchy specific to each country. Although they are extremely simplified, they do have the merit of presenting, in condensed form, a number of stylised facts, which will make it easier to outline our interpretative system.

A) The case of France

The strategies adopted by actors in order to gain access to the hierarchy are very complex in France, in the sense that they combine formal qualifications, professional experience and seniority. This complexity is closely linked to the organisational structures of French firms, which have put in place a system of work organisation dominated technically and organisationally by the notion of job. This notion is the key factor in both the technical management of production and the social management of jobs (job classification). The hierarchy in French firms is based essentially on this job classification system, to which employees gain 
access through a variety of routes and by adopting a range of different strategies. In other words, the hierarchy is sustained by both external and internal mobility. Thus at all levels of the hierarchy, including the highest ones, employees holding the formal qualifications stipulated for that particular level and self-taught people promoted from the lower levels exist alongside each other. It is as if these two categories of actors are constantly competing with each other for vacant jobs by enhancing, in their own particular ways, the human capital they possess. A struggle of this kind tends to encourage the actors to adopt their own independent, and sometimes highly creative strategies, but there can be no doubt that it also tends to weaken the identity of each category and, ultimately, to undermine the legitimacy of the hierarchy.

\section{JAPAN}

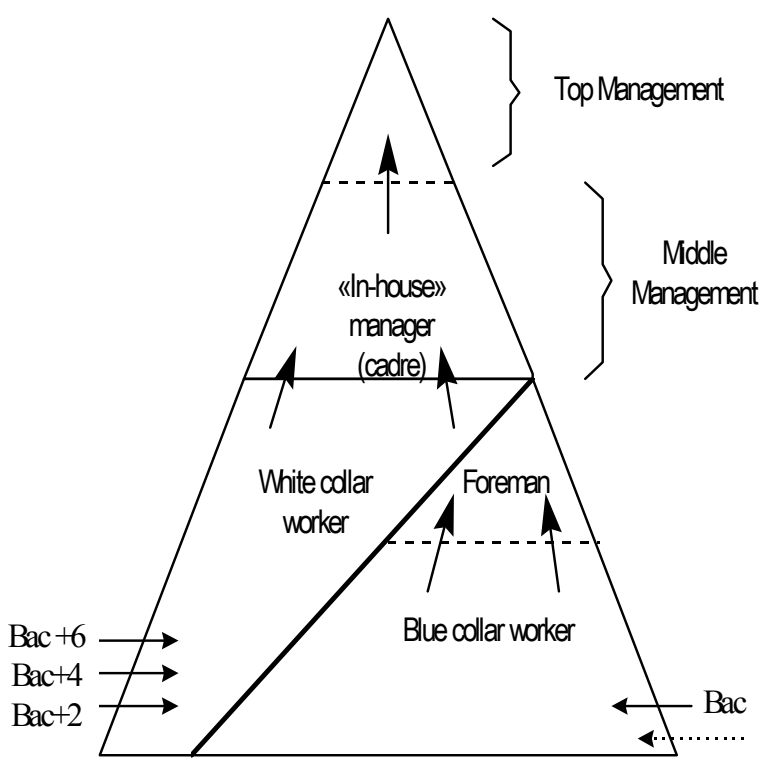

Source: H. NOHARA (1995) LEST-CNRS
FRANCE

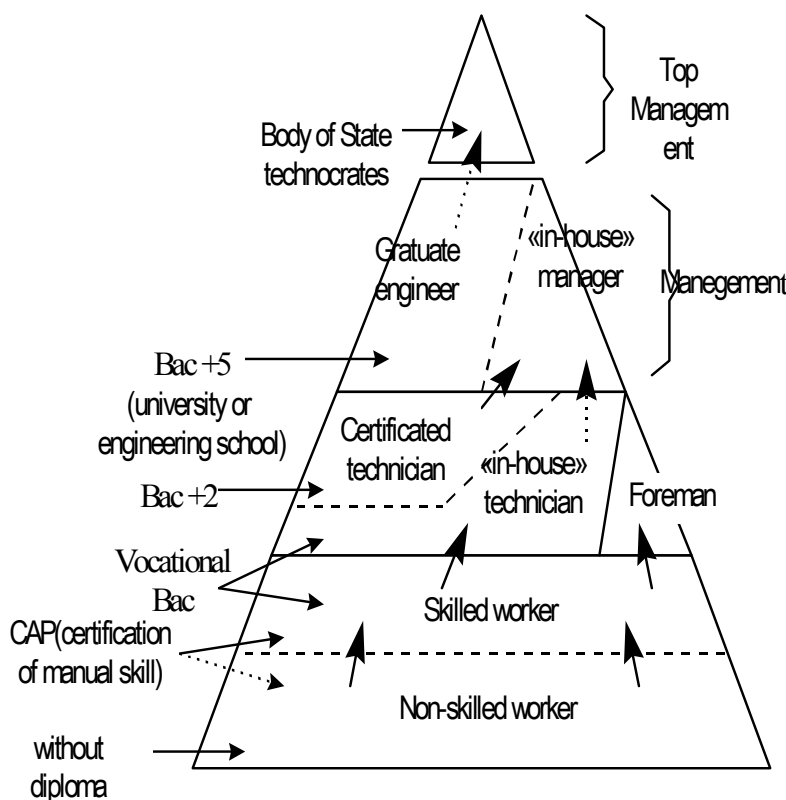

Nota:The level of education corresponds to a number of schooling years after the baccalaureat(high school graduate) 
These two modes of access to the hierarchy naturally have their own internal logics:

The match between formal qualifications and jobs is based on the collective agreement negotiated between the social partners and legitimated by the state. These rules are external givens to which French firms have to acquiesce. At the same time, the educational system selects pupils for its various levels and courses, thereby preparing them for specific occupational categories: those with five years' higher education are graduate engineers (or cadres), those with two years' higher or further education are technicians, those with the vocational baccalauréat or CAP (certificat d'aptitude professionnelle, or vocational training certificate) are manual workers, and so on. This labour supply, which is already extremely hierarchised, is also finely graded and highly specialised: science graduates from the universities are often destined to become researchers, engineers from the major grandes écoles to be senior managers or executives, engineers from the minor grandes écoles to work in production, and holders of lower-grade qualifications (brevet de technican supérieur or the two-year diplome universitaire de technologie) to be senior technicians. This evaluation of individuals, carried out on the basis of educational selection, extends directly into the hierarchy and remains very much in evidence throughout an employee's entire career. The importance attached to educational qualifications gives rise to various occupational identities that are used to legitimate the existence of hierarchically arranged "territories" and the strategy of external mobility in the labour market. This segmented situation gives rise to a certain imbalance of power in the organisation of creativity in manufacturing industry: those engaged directly in production (i.e. technicians and manual workers) are not allowed to play as full a role as possible in the technical aspects of product design and manufacture, since engineers tend to "parachute" their ideas on to the shop floor without consultation. In other words, the existence of hierarchised territories hinders the development of wide-ranging dialogue between the design and production functions and of sufficiently rigorous compromises between technical "inventiveness" and manufacturing feasibility. Faithful to the doctrine of Taylorism, France tends to produce a hierarchy characterised by a clear split between design and production (Boyer 1990). The former function is overvalued, while the latter is not given sufficient consideration.

Over and above the influence over organisational structures exerted by educational qualifications, firms also have some scope to take the initiative in constructing the hierarchy. In so doing, they are explicitly recognising the allegiance that employees without formal qualifications develop through the stabilisation of their position within the firm. This interaction between the firm and employees is based on highly personal strategies. The ambition of semi-skilled manual workers is to be promoted to the skilled worker category, while that of technicians is to become engineers or cadres. The system of internal promotion between the various categories serve as an incentive mechanism for those wishing to become involved in their work, to invest in continuing training or simply to escape from the status of manual worker and the unfavourable conditions associated with it. Thus this mechanism creates groups of self-taught 
employees, such as the so-called "in-house" technicians or cadres, who coexist with their formally qualified colleagues but are unable to transfer the standing they have acquired within the firm to the external labour market.

B) The case of Japan

In comparison with France, the hierarchy in Japan is based simultaneously on continuity and discontinuity.

As far as discontinuity is concerned, three different dimensions should be highlighted. The first is the more or less complete closure of the organisation to its external environment. The hierarchy in Japanese firms is constructed almost exclusively on the basis of career paths that are internal to the organisation. As a result, any links with the external labour market are confined to a certain number of low-status jobs, while access to the higher level or to managerial or supervisory positions cannot be gained through external mobility. This detachment from the external labour market tends to channel actors towards internal strategies (promotion) and to create a "balkanised" labour market. This fragmentation is fairly consistent with the system of educational qualifications, which is not intended to "qualify" the labour force but simply to guarantee its "potential". Thus educational qualifications, even the best (awarded by one of the best universities), are unable to acquire any measure of transferability and thus be recognised in different organisations. The second dimension concerns the gender segregation in the labour market. The division between male and female wage-earners, which reflects a powerful social norm governing the differentiation of gender roles, is proving to be very resilient in Japan. While the educational certification protects relatively the female workers against the job and wage discrimination in France, a lack of socially recognised skill-standard weakens their position in Japan. Irrespective of status or the nature of their employment contract, female employees are seldom allowed to develop their careers to the full. They are, to a great extent, excluded from the mechanisms governing progress up the hierarchical ladder, because they don't have the same training opportunities as men or often are obliged to abandon their careers for family reasons. The third dimension is the split between the manual space ("blue collar" category) and the non-manual space ("white collar" category). This split manifests itself in the absence of any link between the "blue collar" and "white collar" categories. In other words, manual workers, who very often are high-school graduates, are allocated first to simple tasks and acquire experience by rotating between different jobs, thereby becoming "functionally flexible". However, they remain confined to their own particular career path, which advances within a relatively closed space from which the only exit is promotion to a supervisory job (position of foreman). Nevertheless, this compartmentalisation of the various categories, which is not necessarily status-enhancing in Japan as it is in France, does not seem to sap the motivation of manual workers when it comes to skill development. The manual career path, whose separateness is compensated for with a wide wage curve, creates its own logic of incentive, involvement and integration into the organisation. This logic is further strengthened by the high degree of continuity between the manual category and supervisory positions, in the sense that 
promotion to such a post represents the natural and legitimate culmination of the manual career path.

As far as continuity is concerned, mention should be made of the importance of the "melting pot" in which new recruits are immersed in transcending the various divisions between statuses and categories, particularly in the "white collar" category. Whether they have received two, four or six or more years of higher education, university graduates constitute a more or less undifferentiated population of recruits from which, after a period of between ten and fifteen years, the new generation of senior managers will be selected. In other words, the entire population of new recruits is treated as a single reservoir of human resources from which specific resources are gradually extracted. Thus the process of differentiation takes place over time and is based more on what the new recruits learn than on the status or category to which they belong at the beginning of their careers. Moreover, the "technician" category has neither a place in the classification system nor any real equivalent in Japan. This is why the technician category is not included in the Japanese diagram. The tasks performed by technicians in France are allocated to experienced manual workers at the end of their careers and to foremen, as well as to university graduates with six years' higher education at the beginning of their careers. This break-up of the technicians' role may well explain why the boundary between design and production in the Japanese hierarchy is somewhat ill-defined. The separation of tasks that is one of the guiding principles of Taylorism is certainly not eliminated, but it is attenuated to a certain extent, if not modified (Nohara \& Silvestre 1987). This phenomenon reveals the extent to which occupational categories and the division of labour are "social constructs" that depend on national contexts.

Not having any immediately useful skills, all these new recruits undergo the same occupational and organisational apprenticeship. Their skills develop during a long process of socialisation: the new recruits begin by exploring technically limited tasks carrying little responsibility, gradually extending their sphere of competence by moving on to related tasks. The hierarchy of educational levels and university degrees remains in abeyance during this period of apprenticeship. However, its effects make themselves felt as individuals advance along their career path, and particularly when it comes to promotion up the hierarchy. Indeed, although the majority of university graduates advance at more or less similar rates for almost ten years, the principle of selection and competition begins increasingly to emerge. Thus 35-40 is a pivotal age, since it is then that selection to the first rung of the management ladder takes place. This selection is based not on a shot in the dark or on a gamble on any particular individual, but rather on the system of assessment that constantly evaluates, on an annual basis, each individual's progress in the learning process and his/her ability to cooperate and contribute to the collective effort. This encourages employees to incorporate long-term considerations into their career strategies. Nevertheless, sustained and exacting competition of this kind finishes by producing the hierarchy at around age 40 and leads to the differentiation of university graduates into managers and non-managers. This competition continues subsequently, in an extremely selective way, as employees progress towards the upper echelons of the 
hierarchy. This structuring of internal career paths, which combine collective cooperation and individual selection, might well correspond to the principle of "tournament competition" outlined by Rosenbom (Rosenbom 1982). However, the question remains as to why and how Japanese firms manage to organise such a slow selection process that seems in some respects to be demotivating and in others to be one element in the production of cooperation. Thus the management team, including senior executives, is produced over time as each generation succeeds the previous one. As a result, a high degree of continuity is maintained with the base of the pyramid. In this way, the hierarchy acquires a dynamic, temporal element rather than being simply vertical.

\section{II - The transformation of the Japanese HRM model}

We shall now turn our attention to examination of the type of change the Japanese HRM model is undergoing in a period of long recession. This model, outlined above, contains a set of rules and practices capable of structuring the organisation of the internal market. These rules and practices are not immune to external shocks. On the contrary, they react either by encouraging certain patterns of behaviour or certain kinds of social relationships or by obstructing the emergence of new behaviour patterns that are inconsistent with the principles underlying them. In some instances, they are also capable of renewing themselves by laying a new foundation for the social infrastructure on which the interplay between the actors is based. In this case, the new elements emerge sometimes at the heart of the central regulatory mechanisms and sometimes on the periphery, although it is difficult to distinguish what is merely an extension of the existing model from what might be considered a radical alteration of it. Faced with the complexity of these real shifts, there is a need to equip ourselves with a methodology capable of dealing adequately with the question of change. An interesting path has already been opened up by Silvestre (Silvestre 1986) who put forward a typology of mechanical, organic and structural changes:

i) Mechanical change denotes a change in the social behaviour of actors or institutions that takes place only on the margins of the system without affecting the central core of the trade-offs that enable the system as a whole to adapt. Such a change is, therefore, a mechanical effect produced by the absorption of external shocks.

ii) Organic change denotes a certain plasticity in the most widely legitimated and accepted rules that constitute the heart of the system. Although the central principles of the system are mobilised in order to absorb tensions and conflicts, that mobilisation is achieved through an extension of the sphere in which those principles can be applied rather than through any fundamental change in their nature.

iii) Structural change denotes a response that seeks to modify the fundamental principles of the system when the shocks disturb its centre of gravity. This triggers a process of change affecting social behaviour and requiring new trade-offs. Institutional change of this magnitude cannot take 
place without the actors engaging in a collective learning process or the emergence of new actors.

Like so many others, this typology is not perfect. In particular, it is static and takes no account of the fact that events take place in time. For example, it may be that a change that seems to be mechanical at one point could end up by changing over the long term into a structural change, as a result of the threshold effect or for other reasons. Or, conversely, apparently "radical" changes can become commonplace as they are worn away by routine and time. Despite this problem, which remains unresolved, the typology outlined above does make it possible to identify more clearly the responses of Japanese firms to the current crisis and to understand the consequences of those responses for the Japanese model of HRM.

According to the composite index compiled by the Economic Planning Agency the recession that began to take hold in 1991 bottomed out in the last quarter of 1993, but in the absence of any clear sign of an upturn it has remained dormant until today. Many firms, having built up surplus capacity by over-investing at the end of the 1980s, have had to face a crisis of profitability. The continuing rise of the yen against the dollar has worsened the situation by weakening their international competitiveness. During this recession, the longest Japan has ever experienced, many firms have had to embark on a restructuring of their activities, which has been accompanied by job losses. Nevertheless, the extent of these losses, although considerable, does not appear to be any greater than those that followed the first oil shock. On the other hand, they have been spread over a longer period. This slowness in adjusting the size of the workforce is undoubtedly linked to the nature of corporate governance in Japan, which is less subject to short-term financial discipline and tends to put off radical restructuring of industrial activities and to avoid taking drastic measures if at all possible. This is consistent with what various studies have already revealed of firms' behaviour when faced with the need to adjust the size of their workforce to demand;

Their first reaction is to reduce the volume of overtime, while at the same time freezing recruitment. Secondly, they do not rehire those employees on fixed-term contracts, while at the same time reallocating workers among the various establishments within the group to which they belong. Finally, if they fail to make a profit for two consecutive years, they negotiate "voluntary" redundancy for older members of the workforce, who tend to be more expensive than their younger colleagues. The bargaining often focuses on an increase in the lump sum allowance, which in theory is proportional to seniority. As a result, redundancies are rather rare, except in the case of bankruptcy. The same pattern of behaviour has been observable in the current recession, albeit with a few modifications, which confirms the existence of a routine behaviour pattern among firms.

Over and above this general outline of labour market trends, which requires specific statistical studies, we shall try to discover how the whole set of rules and practices has reacted to the economic situation and whether those reactions have led to changes in the Japanese model of HRM. 


\section{II-1Mechanical change}

This crisis has, once again, weakened the position of female wage-earners, most of whom exist on the periphery of the central employment regulation system. The weak position of women has three dimensions:

Firstly, because of the reduction in recruitment levels, it has now become more difficult than in the past, when it was normal for school-leavers and new graduates to go straight into firms, to gain access to the internal labour market for young people leaving the educational system. This increased selectiveness disadvantages female graduates in particular, since the office jobs that have been their traditional destinations are much reduced in number as a result of computerisation. This situation has led them either to accept the various atypical types of employment contract or to delay their entry into the labour market.

Secondly, the relationship between young women and firms is one of mutual mistrust, in that their "temporary" presence in the firm and the lack of investment devoted to them creates a vicious circle. This so-called "statistical" discrimination is based on a principle that is diametrically opposed to that of a mutual commitment to long-term investment in human capital that applies to male employees. Although they are integrated into the internal labour market, and despite the introduction of equal opportunities legislation in the employment sphere, women do not have the same opportunities to make a career for themselves as men. In fact, most of them abandon their careers, not so much nowadays when they marry as when their first child is born, but in any event before they have placed their feet on the first rung of the management ladder. Thus women still account for only $3 \%$ of the total population of "supervisors". Similarly, it is significant that the quit rate for women aged between 20 and 29 has remained around 25\% per year during the recession (Annual Survey on Employment Trends, Ministry of Labour, 1994).

Finally, the recession has led to an increase in the number of married women in precarious employment relationships and accelerated their move into the external labour market. In 1995, more than $20 \%$ of the wage-earning population (10 million out of a total of 47.8 million), $75 \%$ of them women, were on part-time, temporary or other types of precarious employment contract (Annual Report on the Labour Force Survey, 1996). Thus the number of outsiders has increased.

All in all, firms' initial response to the recession has been to marginalize an increasing share of female wage-earners, who exist on the periphery of the wage/employment trade-off. This change is essentially quantitative in nature. However, it may well be asked whether the further continuation of such a trend will not, in the long term, begin to undermine the interests of firms themselves. In the light of the forecast shortage of young workers in the near future and of rising qualification levels among young women, Japanese firms will be forced to integrate women more closely into their organisational structures, a move that will lead to profound change in their model of HRM.

\section{II-2 Organic change}


The most widely respected wage/employment trade-off is the mutual, long-term commitment between firms and their (male) employees that is symbolised by the notion of the "lifetime employment". Firms undertake to guarantee employees a job and a minimum level of career advancement at each stage of the life cycle; for their part, employees undertake constantly to improve their skills, which is the best guarantee of the firm's long-term development and survival, while waiting for their efforts to be rewarded. It is this system of mutual expectation, fashioned in the course of Japanese social history, that provides the basis for the production of the hierarchy (Nohara, 1993). Although it is based on a ethnological notion of trust, such a collective cognitive system (Favereau, 1990) nevertheless has permanently to demonstrate its legitimacy while at the same time confronting the harsh laws of the market economy. To this end, two additional, interacting mechanisms have developed in order to ensure that the system survives in the face of economic vicissitudes.

Firstly, Japanese firms tend to favour a mode of development based on endogenous growth, which is achieved through diversification of their activities. This phenomenon is particularly evident in "mature" industries such as iron and steel, textiles and basic chemicals, but is by no means confined to them. Some firms try to convert declining industries into industries of the future, by making maximum use of their internal resources, and particularly their human resources. Others harness to their own ends a generic technology, such as micro-electronics or materials science, in order to create new products and enter new areas. In contrast to European countries, where restructuring is synonymous with mergers, take-overs and concentration, often leading to job losses, the process of industrial reorganisation in Japan tends to be accompanied by the creation of subsidiaries and thus of "pyramid-shaped" groups of firms. Such a strategy, based on long-term considerations and the exploitation of internal resources, is not, of course, unconnected with the form of corporate governance. Characterised as it is by a relative lack of stockholder control and pressure to generate short-term profits, it allows business gambles to be planned collectively over the long term, which entails risks that are more difficult to control than if a purely financial strategy was adopted.

Secondly, this trend towards internal diversification goes hand in hand with the mechanism of internal labour mobility. The Japanese system of work organisation already has a certain degree of flexibility, created through job rotation (Koike, 1976). Since pay is not directly linked to any particular job or task, the definition of which tends in any case to be vague, employees are less likely to jib at switching functions. On the contrary, their notion of a career tends to include a number of changes, whether it be allocation to a new job, a period of learning or even a transfer to a different establishment. Although there is some resistance to internal mobility, and local disputes certainly occur, firms are able to mobilise this mechanism, often giving joint control to the trade union, in order to adapt to fluctuations in output, the introduction of new technologies and industrial restructuring. For example, in 1993, 804,000 male employees moved between establishments within the same company; this was equivalent to one-third of the total exit flows (i.e. 2,360,000 male employees left their employers in that year - 
source op. cit.). Internal fluidity of this kind gives firms a high degree of organisational flexibility. There is no doubt that this kind of regulation was spontaneously adopted in response to the destabilisation of the productive system caused by the current recession.

However, this mode of regulation, confined as it is within the firm, has its limits, as well as a certain tendency to break out beyond the confines of the firm, making it necessary to extend its field of application. In an economic situation in which the number of surplus workers "hoarded" by manufacturing firms is put at more than a million, firms are transferring part of their workforces, mainly to subsidiaries, but also to sub-contractors or client companies. It is mainly employees aged 45 and over who are being offered a transfer to subsidiaries. Most seem to accept the transfer as a second-best option, while in some cases mobility has been enforced, even if the employees concerned retain their original employment contract. This practice of transferring workers for longer or shorter periods, which is known as "shukko", existed before the recession, but seems to have become more prevalent and now affects between 350,000 and 400,000 people (source op. cit.). This reflects an extension of the boundary of the internal market towards the group. This phenomenon may be interpreted as an extension of the rules of the existing trade-off which, despite local tensions, makes it possible to reconcile the principle of "lifetime employment", reductions in employment levels and the diffusion of innovative capacity within the group. We shall use the term "organic" to denote such a change, since the fundamental rules of the trade-off, based on a complex social transaction, here demonstrate their plasticity in adapting to new situations.

Nevertheless, as the recession persists, the limits of such plasticity are constantly being pushed back. "Shukko", in which the main employment conditions of transferred workers are retained because the original employment contract remains in force, is increasingly being replaced by "tenseki", which denotes a permanent transfer and the rescinding of the original contract. Most of those transferred permanently experience a deterioration in their employment conditions. This transfer has much in common with the "reclassification" that is a feature of many of the social plans drawn up by French firms. In Japan, however, this "reclassification" mainly concerns white-collar workers aged 50 and over, including managers. Taken in conjunction with the accelerated ageing of the wage-earning population, an excess of supervisory staff weighs heavily both on the organisation of the firm and on its wage bill. From the point of view of the hierarchical approach, mobility of this type does not simply reflect increased selectiveness in promotion decisions, nor a "funnel" effect caused by the filtering out of the least effective members of the supervisory category. Rather, it may well call into question the validity of the existing incentive mechanisms, by undermining the trust on which the mutual commitment is based and destabilising to some extent the key category of employees that embodies the most entrenched employment norm. If it continues to gain ground, this phenomenon may well finish by opening up cracks in the construction of the hierarchy, which would be an indication of a shift towards structural change. 


\section{II-3 Structural change}

A long period of stagnation is conducive to a questioning of management practices that have become routinised. HRM practices are not immune to this tendency and many firms are trying, in a voluntarist way, to experiment with their longest established practices. Over and above the influence of the recession itself, these trends also underlie the changes taking place in the productive paradigms as a regime based on the technological cycle of imitation/assimilation/development gives way to one in which the emphasis is on the creation of new technological resources. As a recent report by the Japanese employers' association shows (Nikkeiren, 1995), HRM in that country is currently experiencing a proliferation of institutional innovations.

i) One of the most prominent characteristics of these innovations is the trend towards a reconfiguration of the various components of the work process in such a way that they become both more autonomous and more interactive. This reorganisation is leading to a reduction in the (overall) size of the organisation (downsizing), a flattening of hierarchies and a simplification of the horizontal and vertical channels of communication. In concrete terms, it manifests itself in the elimination of jobs and levels of the hierarchy through the adoption of project-based organisational structures and the abolition of the distinction between managers and those engaged directly in production tasks. In effect, hierarchical organisational structures are being replaced by networks of autonomous but interconnected "cells". This trend is blurring the boundaries of the organisation, and stands in sharp contrast to the organisational principles that structure internal labour markets in general and the production of the hierarchy in Japan in particular.

ii) The second aspect concerns the various attempts to renew incentive mechanisms, particularly the wage system, long considered excessively rigid and ill-suited to the new competitive conditions. Attempts are being made to put in place a new system, albeit one that takes a wide range of different forms, that combines greater flexibility with increased competition. Some firms have already introduced "nemposei", a lump-sum salary which is renegotiated annually and depends to a large extent on individual performance. Performance-related pay has the advantage of fluctuating, both upwards and downwards, in accordance with individual results, and of individualising to a large extent the remuneration of each employee. Such strengthening of incentive mechanisms is intended to encourage autonomy and individual creativity, particularly among white-collar workers, whose productivity is considered rather mediocre, even if it means sacrificing some of the benefits of cooperation. However, this new mechanism would seem to leave unresolved the question of agreement on the criteria for assessment of individual performance and to come into conflict frequently with the feeling of equity that employees have hitherto shared.

iii) The third aspect concerns the increasingly heterogeneous nature of the wage-earning population. Many firms are seeking to create a certain degree of heterogeneity in their workforces, which runs counter to the traditional emphasis on company culture, regarded as a integrative and homogenising influence on the workforce. The relative homogeneity and compactness of the wage-earning 
population, which were conducive to the diffusion of information and to the development of collective learning at a time when Japan was striving to catch up technologically with the industrialised West, are becoming one of the factors blocking creative initiatives that depart from the norm. As a result, new practices are being introduced. Some firms are hiring high-level specialists on fixed-term contracts and paying them high salaries well in excess of the normal pay scale in compensation, others are establishing a "fast track" for promotion to management positions by selecting young employees at a very early stage and yet others are diversifying the channels through which young graduates are recruited by changing their traditional relationships with the universities.

iv) The fourth aspect concerns firms' initial attempts to externalise parts of the HRM function, such as recruitment, training or even employee evaluation. Since HRM has traditionally been a strictly internal and confidential matter, firms have built up large departments to deal with this area of their activities and have seldom had recourse to outside services. The standardisation of management tools that will result from this externalisation will undoubtedly have an effect on external mobility.

Some of these institutional innovations constitute a direct assault on the most widely legitimated rules on which the Japanese model of HRM is based and are intended to create new patterns of behaviour among employees. Indeed, close observation of what is happening on the ground shows that the creation of new rules is being accompanied by innumerable attempts at mobilisation involving the social partners or interactions between individual actors. In this sense, what might be called structural change already exists in embryo although, taken as a whole, the micro-innovations that are taking place are not coming together to form a clearly defined, coherent whole, in other words a new model of HRM.

\section{By way of conclusion}

These micro-innovations may remain in a latent state for a long time, or they may fail to survive transplantation into the existing structure and eventually wither away. Nevertheless, the possibility of a radical change in HRM practices is not excluded either: certain actors are already engaged in - contradictory collective learning processes. Even though they seem to have little room for manoeuvre at the moment, the space in which the social partners interact is less confined than in the past. Those interactions may become very extensive, particularly if financial globalisation ended by changing the Japanese form of corporate governance, which has to date been responsible for ensuring compatibility between the slow rate of return on equity and the mutual, long-term commitment on employment. 


\section{Bibliography}

Akerlof,G and Yellen, J (1986) : Efficiency Wage Model of the Labor Market, Cambridge University Press : Cambridge.

Aoki, M (1988): Information, Incentives and Bargaining in the Japanese Economy. Cambridge University Press :Cambridge.

Becker, G (1962) : Investment in Human Capital : A Theoretical Analysis. In : Journal of Political Economy, Vol.70. P.9-49.

Becker, G (1964) : A Theory of The Allocation of Time. In Economic Journal, Vol.75. P.493-517.

Beret P (1992) : Salaires et marché internes: quelques évolutions récentes en France. In : Economie appliquée, Vol.XLV. N 2.

Boyer, R (1990): New Directions in Management Practices and Work Organisation, General Principles and National Trajectories. Working Paper $\mathrm{N}^{\circ}$ 9130.CEPREMAP, Paris.

Doeringer, P and Piore, M (1971): Internal Labor Markets and Manpower Analysis. Heath Lexington Books.

Dore, R (1973) : British Factory - Japanese Factory, The Origins of National Diversity in Industrial Relations. University of California Press.

Favereau, O (1989) : Marchés Internes, Marchés Externes. In :Revue Economique $\mathrm{N}^{\circ}$ 40. p.273-328.

Glaude M (1986) : Ancienneté, expérience et théorie dualiste du marché du travail: une étude sur données individuelles. In : Economie appliquée Vol.XXX N${ }^{\circ}$.

Granovetter, M (1985) : Economic Action and Social Structure : The problem of Embeddedness. In : American Journal of Sociology 91 (3), p.481-510.

Koike, K (1976): Shokuba no rodokumiai to sanka (Trade-Union and Participation at the Level of Workplace), Toyokeisai-shinposha, Tokyo.

Koike, K (1981) : Nihon no jukuren ( Skill Formation in Japan ), Uhikaku, Tokyo.

Maurice, M, Sellier, F and Silvestre, J.J, (1986): The Social Foundations of Industrial Power :a Comparison of France and Germany. The MIT Press, Combridge, London.

NIKEIREN (Ed.) (1995) : New Japanese-Style Management System. Tokyo.Nikeiren.

Nohara, H et Silvestre, J-J(1986) : Industrial Structures, Employment Trends and The Economic Crisis: The Case of France and Japan in the 1970s. In : Tarling, G (éd.) : Flexibility in The Labor Markets. Academic Press. London.

Nohara, H (1987) : Les Acteurs de la Dynamique Industrielle au Japon. Rapport de recherche du LEST, Laboratoire d'Economie et Sociologie du Travail. Aix-en- Provence.

Nohara, H (1993) : Le Syndicat d'Entreprise et le Micro-Corporatisme au Japon ; Acteurs, Compromis et Dynamique Temporelle. In : GAZIER, B (Ed.) : Emploi, Nouvelles Donnes. Economica, Paris. 
Nohara, H. (1995): Les Salaires en France et au Japon: Comparaison des Structures de Salaires dans l'Industrie Manufacturière des Deux Pays de 1978 à 1986. In : Travail et Emploi $\mathrm{N}^{\circ} 62$. P.59-71. Paris.

RODOSHO (Ed.) (1994) : Koyo doko chosa 1993 (Annual Survey on Empoyment Trends 1993).Rodosho, Tokyo.

Sellier, F(1984): La Confrontation Sociale en France 1936-1981. Presse Universitaire de France. Paris.

Silvestre, J.J (1986) : Marchés du Travail et Crise Economique : De la Mobilité à la Flexibilité. In : Formation - Emploi N 14. P.54-61.

SOMUCHO (Ed.) $(1995,6)$ : Rodoryoku chosa nenpo (Annual Report on the Labour Force Survey 1995,1996). Somucho Tokeikyoku, Tokyo.

Ujihara, S (1958) : Nihonteki Rodoshijo No Mokei (the japanese model of labour market), Tokyo University Press.

Weitzman, M.L (1984) : The Share Economy, Harvard University Press.

Williamson, O.E (1975) : Markets and Hierarchies. Free Press, New York. 